published in 1913, contains an account of his own work, especially that on photo-electric fatigue. "The Quantum and its Interpretation" (1928) was, to quote his own words, "not a treatise on the quantum theory but an attempt to deal with the baffling problem of the nature of the quantum". Although no mean mathematician, he was never content with a purely mathematical representation of phenomena. Wherever possible, he tried to present a picture in terms of a 'model', and he endeavoured "to take a middlo course between a mathematical and a purely descriptive treatment". His "Electrons and Waves" (1932) is devoted to the dilemma of particles versus waves. Allen and Moore's "Text Book of Practical Physics", first published in 1916, after frequent reprinting, is now in its third edition, and his "Text Book of Heat", written jointly with R. S. Maxwell, appeared in 1939.

He was elected a Fellow of the Physical Society in 1906 and of the Royal Society of Edinburgh in 1920. He served on the Council of both those Societies and was awarded the Makdougall-Brisbane Medal by the Royal Society of Edinburgh. $\mathrm{H}_{e}$ was admitted to the fellowship of the Royal Society in 1930, and this honour he shared with his brother, Edgar Johnson Allen, who was for many years director of the Marine Biological Laboratory at Plymouth. When he retired from the chair of natural philosophy in 1944, the University of St. Andrews elected him professor emeritus and conferred on him the degree of LL.D.

Prof. Allen was naturally shy and retiring, and only those privileged to know him most intimately realized the depth of kindness which lay behind his quiet dignity of manner. His junior colleagues gained much from his advice and encouragement, and his students will always remember him for his lucid style as a lecturer. Every lecture which he delivered was thought out with care and presented with the utmost precision and elarity. His whole life was devoted to the search for truth. There are many who mourn his death, which took place at the home of his daughter on April 27.

D. JACK

\section{Prof. J. P. Hill, F.R.S.}

Prof. J. P. Hill died suddenly on May 24, in his eighty-first year. His first scientific paper was published in 1892 ; his most recent four years ago ; and only three days before his death he was discussing with the librarian of the Zoological Society the placing of the illustrations of Part 7 of his series of papers on the development of the Monotremata, a paper that is now in the press. His spar of active scientific work thus covered a period of more than sixty years. There can be few scientists who have enjoyed so long and so fruitful a life of research.

James Peter Hill was the son of Scottish parents. After attending the Royal High School in Edinburgh, he joined the Royal College of Science in London, before returning to Edinburgh, where he studied zoology under Cossar Ewart. His first appointment, in 1892, was as demonstrator in biology in the University of Sydney. From this office he was promoted, in 1904, to the post of lecturer in embryology. In 1906 he returned to England, to occupy the Jodrell chair of zoology and comparative anatomy in University College, London. He relinquished this appointment in 1921, to take up a chair of embryology and histology, which was specially created for him as part of the reorganization of the Department of
Anatomy in University College that was carried out by Elliot Smith with the support of the Rockefeller Foundation. He retired from this post in 1938, when he reached the age of sixty-five. He was elected to the Royal Society in 1913, and was awarded the Darwin Medal in 1940. He was an honorary member of several foreign academies of science.

The scientific circle to which J. P. Hill was introduced as a young man in Sydney included the late Prof. J. T. Wilson, who afterwards became professor of anatomy in Cambridge; Sir Charles Martin, who was later professor of experimental pathology in the University of London; and the late Sir Grafton Elliot Smith, who had already begun his now classical studies of the morphology of the vertebrate brain. Hill's first research interest was in the Enteropneusta, but he very soon turned his attention to the embryology of the monotremes and the marsupials, a subject which remained his chief interest throughout his long career. His first paper in this field, published in collaboration with Martin, was entitled "A Platypus Embryo from the Intrauterine Egg". This proved to be the start of a systematic study of the embryology of the duck-billed platypus, which he carried out mainly in collaboration with $J$. T. Wilson. $\mathrm{He}$ also investigated the process of fertilization in monotremes, and the manner of formation of the corpus luteum, the phases of development of which he was able to correlate with the functional stages of the reproductive cycle. In addition, he devoted himself to the problem of the placentation of Perameles, showing that this animal has an allantoic placenta, and to the systematic study of the morphology and development of the urogenital organs in the Marsupialia. When he returned to England his attention became partly transferred to the embryology of Eutheria, and particularly to the development, of the primates, including man. One of the most important of his publications is his 1932 Croonian Lecture of the Royal Society, on "The Developmental History of the Primates". This monograph provides what is now rightly regarded as the classical account of the blastocyst, of the manner of implantation, and of the formation and structure of the placenta in all the main subdivisions of primates.

Vol. 82 of the Journal of Anatomy, published in 1948, was dedicated to J. P. Hill. Prof. D. M. S. Watson, in a foreword, describes J. P. Hill as a general zoologist of wide interest and encyclopaclic knowledge; and as a man of delightful and unique personality. $\mathrm{He}$ also provides a picture of an enthusiastic teacher; and of a scientist whose quality was not only revealed in his own writings, but also in the work of his research students. For his influence extended not only to his collaborators--J. Brontë Gatenby, Thomson Flynn, E. A. Fraser, A. Subba Rau, to name only a few-but also to numbers of others who, under his guidance and stimulus, undertook research on embryological subjects. J. P. Hill also did much to encourage the work on sex hormones that was proceeding in University College in the later 'twenties and early 'thirties.

It has been said of him that he was too meticulous a scientist, and that he carried a passion for certainty to such lengths that he would wait unnecessarily long to dot the 'i's' and cross the 't's' of his discoreries. A passion for certainty is, however, a fault in the right direction. If it led Hill to withhold from publication certain observations which might well have been published, we can find compensation in the fact that what he did record is of lasting value. 
Those who knew him and whom he stimulated will never forget the slightly quizzical look over the halflenses of his spectacles as he discussed the merit of some particular series of observations. Shortly before he died, he wrote in a letter : "I am getting very old and decrepit, and though I am still trying to do a little work it is becoming more and more of a labour".
Perhaps he was physically decrepit; but intellectually he was unimpaired. At the age of eighty-one he had shown neither any sign of reduced interest in scientific work nor any tendency to lower the standards which had guided him through a career of meticulously accurate observation and single-minded purpose.

S. ZUCKERMAN

\section{NEWS and VIEWS}

Physical and Inorganic Chemistry at Belfast :

Dr. C. Kemball

Dr. Charles Kemball, who has been appointed to the chair of physical and inorganic chemistry in The Queen's University of Belfast, in succession to Prof. A. R. Ubbelohde (see Nature, April 17, p. 710), is a Fellow of Trinity College and demonstrator in physical chemistry in the University of Cambridge. Educated at Edinburgh Academy and Trinity College, Cambridge, he later became associated with Sir Eric Rideal in the Department of Colloid Science at Cambridge, first in research for the Ministry of Supply and afterwards in more academic studies. Here the pattern of his later work took shape, and his early studies of the surface chemistry of mercury and the thermodynamics of adsorption and monolayers fostered an interest in chemisorption and surface catalysis which has culminated in his wellknown studies of the deuteration of hydrides at metal surfaces. Using the mass spectrograph, Dr. Kemball has thrown light on the fundamental aspects of surface reactions, and his papers show him to be a master of clear exposition. During 1946-47 he was awarded a Commonwealth Fellowship and worked in the United States with Sir Hugh Taylor at Princeton University; on his return to Cambridge he continued his research in the Department of Colloid Science. In 1949 he moved to the Department of Physical Chemistry as demonstrator and also became junior bursar of Trinity College. As a teacher Dr. Kemball is well liked by his students and, though his departure is a great loss to chemistry at Cambridge, he carries with him the best wishes of his colleagues for success in his new work.

\section{Automatic Control and Computing at the} National Physical Laboratory: Mr. R. H. Tizard

A NEw Division at the National Physical Laboratory, which has been formed by the amalgamation of the Electronics and the Control Mechanisms Sections, is to be called the Control Mechanisms and Electronies Division. The field to be covered by the new Division is the automatic control of industrial, administrative and experimental operations and the development of techniques and equipment for data processing and computation. An industrial example of such mechanisms is the automatic control of machines producing precision components in large quantities. Not only are the operations speeded up but also personnel can be released from the boredom of repetitive work. It is hoped that this trend will not be confined to the factory floor but that many routine office operations will also be carried out by suitable machines. 'The new Division is represented on a small group formed to study this subject. This group also includes representatives from the Organization and Methods Division of the Treasury and from tho Ministry of National Insurance. The new
Division is developing automatic or semi-automatic equipment to digest test records and similar material and produce it in the form of graphs or typescript ready for immediate use. Many of the techniques employed are electronic in the sense that thermionic valves are used, but the terms of reference exclude radio and acoustic applications. Thus the Control Mechanisms and Electronics Division is interested in the application of all forms of light electro-mechanical devices to special problems. Mr. R. H. Tizard, of the Metrology Division of the Laboratory, has been appointed officer-in-charge of the new Division.

\section{Liaison Officers at the National Physical Labora-}

tory: E. I. Brimelow and A. J. Garratt, M.B.E.

THE application by British industry of results of research from the National Physical Laboratory is fostered by direct contact between the research workers at the Laboratory and individuals in industry, as well as by contributions to the scientific and technical press. It is, however, felt that much more could be done in the way of bridging the gap between the research laboratory and industry. To meet this need E. I. Brimelow and A. J. Garratt have been appointed liaison officers to work with industry. Mr. Garratt is a physicist and an honours graduate of the University of London. He was in the Civil Service from 1940 until 1951, first with the Ministry of Supply (Armament Research Establishment) and later with the Festival of Britain Office as staff physicist. More recently, he has held an appointment in industry and is a scientific adviser to the B.B.C. Television Service. Mr. E. I. Brimelow is a metallurgical engineer and an honours graduate of the University of Liverpool. He was for eight years from 1936 engaged in research at the Royal Aircraft Establishment, Farnborough, on materials for use in aircraft. After two years in industry as a metallurgist and research and development manager, he joined in 1949 the Chief Scientific Adviser's Division of the Ministry of Works, where he remained until transferred to the Building Research Station (Department of Scientific and Industrial Research) in 1950. $\mathrm{He}$ has also served on various technical committees of the British Standards Institution and on advisory committees of the Ministry of Supply.

\section{Sir Richard Owen (I804-92)}

THE first anatomist of his age and one of the greatest of all times, Sir Richard Owen was born at Lancaster one hundred and fifty years ago, on July 20,1804 . Ho studied anatomy at Edinburgh under John Barclay, worked as prosector with John Abernethy at St. Bartholomew's Hospital, London, and at the age of twenty-two became a member of the Royal College of Surgeons of England, in the neighbourhood of which he set up practice. He was soon to become one of the most distinguished truants from medical practice, and it was at the College that 